\title{
QUALIDADE DE VIDA NO TRABALHO NA PERSPECTIVA DOS EMPREGADOS DE UMA INSTITUIÇÃO FINANCEIRA
}

\author{
QUALITY OF WORKING LIFE FROM THE PERSPECTIVE OF THE EMPLOYEES OF AFINANCIAL \\ INSTITUTION \\ DOI: http://dx.doi.org/10.12712/rpca.v5i3.72
}

\author{
Marli Dias Souza Pinto \\ Universidade do Oeste de Santa Catarina - UNOESC \\ marli.pinto@unoesc.edu.br
}

Adélio Alvicio Kemmer

Universidade do Oeste de Santa Catarina - UNOESC

adeliokemmer@yahoo.com.br

\section{Eliane Salete Filippim}

Universidade do Oeste de Santa Catarina - UNOESC

elaine.filippim@unoesc.edu.br

\section{RESUMO}

O presente artigo teve como objetivo identificar e analisar as percepções dos empregados da Caixa Econômica Federal (CEF) da Superintendência Regional Oeste de Santa Catarina sobre Qualidade de Vida no Trabalho (QVT). Trata-se de uma pesquisa exploratório-descritiva com abordagem quanti/qualitativa, que teve como instrumento de coleta de dados a aplicação de um questionário semiestruturado a 329 empregados. Constatou-se que os fatores que geram satisfação dos empregados são a estabilidade e a confiança na Instituição. Quanto aos fatores de insatisfação destacase a sobrecarga de trabalho. Como oportunidades de melhorias, o estudo revelou a necessidade de maior investimento em treinamento e a reformulação geral dos sistemas eletrônicos.

Palavras-chave: Qualidade de vida no Trabalho. Gestão de Pessoas. Instituição financeira.

\begin{abstract}
The present article had as an objective to identify and analyze the perceptions of employees of the Caixa Econômica Federal (CEF) of the Oversight Regional West of Santa Catarina about Quality of Work Life (QWL). This is an exploratory-descriptive research with a quail/qualitative approach that had as a tool to collect data the application of a semi structured questionnaire to 329 employees. It was found that the factors that create employee satisfaction are the stability and confidence in the institution. As for the factors of dissatisfaction is identified work overload. As opportunities to improve the study showed greater investment in training and overhaul of electronics systems.
\end{abstract}

Keywords: Quality of work life People Management. Financialinstitution. 


\section{INTRODUÇÃO}

A Qualidade de Vida no Trabalho (QVT) é objeto de muitas pesquisas e de reflexões significativas, motivadas por fatores impostos pelos novos desafios socioeconômicos, pelo impacto das tecnologias, pelos novos padrões de consumo, dentre outros aspectos. Este novo cenário tem gerado demandas acerca das condições e do bem-estar no trabalho, relacionadas, quase sempre, à diminuição do ciclo de vida dos produtos e dos processos de produção, que mudam constantemente.

Nas organizações são as pessoas que inovam, criam e agregam valor aos serviços e produtos, esta é uma das razões para que estejam motivadas e comprometidas com seus objetivos e com os objetivos da instituição na qual desempenham suas atividades laborais, razão pelo qual devem ter asseguradas a sua qualidade de vida notrabalho.

Este tema tem sido revisado por diversos estudiosos em organizações empresariais e, por vezes parece haver certa saturação da questão. Contudo, embora o tema não seja novo para a teoria, no horizonte das relações objetivas há muito por aprender e, especialmente, por construir, ainda mais quando se trata de instituição bancária. Esses empregados de organizações do setor financeiro nacional são afetados por mudanças que envolvem consideráveis pressões por agilidade na solução das demandas dos clientes e das próprias instituições bancárias. No entanto, estas pressões podem afetar significativamente a QVT desses atores e, por conseguinte, os resultados positivos esperados pela organização.

Neste sentido, o presente artigo busca responder a seguinte indagação: Qual a percepção dos empregados da Caixa Econômica Federal vinculada a Superintendência Regional do Oeste Catarinense, acerca de qualidade de vida no trabalho?

Este estudo teve como objetivo geral identificar e analisar a percepção dos empregados da Caixa Econômica Federal vinculada a Superintendência Regional do Oeste Catarinense, acerca de qualidade de vida no trabalho. Especificamente os objetivos do estudo visam levantar dados demográficos dos empregados objeto do estudo; identificar a satisfação no trabalho em relação ao(s) relacionamentos interpessoais, plano de carreira da instituição, aos benefícios de saúde e auxílio alimentação; analisar o clima organizacional e plano de carreira; e, por fim, descrever a percepção dos empregados pesquisados na CEF sobre a QVT.

A fim de organizar a apresentação dos resultados, o presente artigo encontra-se dividido em cinco seções, sendo a primeira referente à introdução. Na segunda seção apresentam-se, a luz da literatura, estudos teóricos sobre o assunto. Na terceira parte detalha-se com maior profundidade o método de coleta e tratamento dos dados. Na quarta, analisam-se os dados e interpretam-se os resultados e, finalmente, na quinta seção, tratam-se das considerações finais.

\section{REVISANDO O TEMA DA QUALIDADE DE VIDA NO TRABALHO}

O elemento humano passa a ser reconhecido como a peça-chave para a vida das organizações, em que a QVT tem se tornando parte integrante da política e da estratégica organizacional. Este processo visa, geralmente, desenvolver no trabalhador, maior comprometimento com os objetivos da instituição, que variam desde os cuidados estabelecidos pela legislação médica e a segurança do trabalho, até atividades de cunho voluntário, que envolve empregado e empregadores em áreas como o lazer e a motivação, entre outras (LIMONGI-FRANÇA, 2007). 
Estudos publicados mostram que o valor da qualidade de vida encontra-se atualmente incorporado a todos os quadrantes da vida social. Particularmente no que diz respeito ao mundo do trabalho, a ideia de qualidade de vida assume, presentemente, no mínimo, um papel amplamente difundido como instrumento de gestão de pessoas, por parte de um conjunto crescente de empresas, muitas das vezes, com o foco da aplicação da ideia de QVT como ferramenta de incremento de produtividade de quem trabalha (LEITE et al.,2009).

Ferreira, Alves e Tostes (2009, p. 326) escreveram um artigo caracterizando as práticas de QVT em 10 órgãos públicos federais e o resultado que “a gestão de QVT no serviço público federal investigado se caracteriza pelo descompasso entre os problemas existentes e as práticas gerenciais".

As contratações a partir de concursos públicos não privilegiam a avaliação do empregado no cargo em relação às questões de satisfação, motivação e realização. Sícoli (2003) evidencia que

Os estudos sobre Qualidade de Vida no Trabalho têm como abordagem central o comportamento humano na organização, especialmente no tocante à satisfação do trabalhador na realização das tarefas inerentes ao seu cargo, procurando identificar o que faz o homem trabalhar melhor e mais satisfeito (SíCOLI, 2003, p. 23).

As políticas de Recursos Humanos nas organizações têm estimulado maior qualificação profissional, para que os empregados continuem competitivos ao ingressar no mercado de trabalho. Nas instituições públicas, como é o caso da CEF, a seleção ocorre por meio de concurso público, não possibilitando que os requisitos referentes à competência (conhecimento/habilidade/atitude), sejam relevantes na contratação, mas somente o componente conhecimento.

Alguns autores da área de pessoas afirmam que o trabalho humano é atividade fundamental que possibilita a mudança do mundo e as transformações da existência humana, na realização da tarefa, impulsionados a concentrar esforços na busca de fontes de autoidentificação e de significado pessoal em outras atividades. Sícoli (2003) afirma que os estudos sobre motivação desenvolvidos por Maslow (1954) constituíram-se em um marco importante para o estudo da Qualidade de Vida no Trabalho. Sendo o comportamento de uma pessoa motivado pela necessidade de satisfação de uma hierarquia de necessidades, iniciando-se pelas necessidades fisiológicas, de segurança, sociais, de autoestima ou de reconhecimento de si mesmo e de reconhecimento pelas pessoas ou organizações e, finalmente, as necessidades de realização pessoal.

A motivação dos trabalhadores, seja qual for o tipo de organização, está relacionada a fatores que produzem: 1) Satisfação, relacionada ao conteúdo da tarefa; e 2) Insatisfação, relacionada ao ambiente de trabalho. Deste modo, uma organização deve oferecer aos seus trabalhadores, compensação justa e adequada; condições de trabalho também adequadas; possibilidade de uso e desenvolvimento de suas capacidades; oportunidade de crescimento e segurança; integração social na organização; constitucionalismo; trabalho e espaço total de vida; relevância social da vida no trabalho (WALTON, 1973 apud RUGISKI et al.,2005).

Se o empregado em uma organização é exigido dentro de limites pessoais estabelecidos, ele vai reagir de acordo com a pressão e desafios percebidos. Com isto, tem se observado que a Qualidade de Vida no Trabalho tem se tornando, cada vez mais, uma preocupação para as empresas, devido à ligação que existe entre condições adequadas para realização de um trabalho e a produtividade. Visando sintetizar alguns aspectos relevantes para nortear a 
pesquisa, no Quadro 1 são apresentados alguns critérios de avaliação utilizados pelos autores estudados sobre QVT.

\begin{tabular}{|l|l|}
\hline \multicolumn{1}{|c|}{ Autores } & \multicolumn{1}{c|}{ Critérios } \\
\hline Lacaz (2000) & $\begin{array}{l}\text { Participação efetiva do trabalhador no processo de trabalho e planejamento e } \\
\text { negociação das políticas de RH. }\end{array}$ \\
\hline $\begin{array}{l}\text { Ayres et al. } \\
(2000)\end{array}$ & $\begin{array}{l}\text { Compensação justa e adequada. Condições seguras e saudáveis de trabalho. } \\
\text { Oportunidade imediata de uso e desenvolvimento das capacidades humanas. } \\
\text { Oportunidade de contínuo crescimento e Segurança. } \\
\text { Integração social na organização do trabalho. } \\
\text { Constitucionalismo na organização do trabalho e relevância social da vida de trabalho. }\end{array}$ \\
\hline $\begin{array}{l}\text { Rugisk et al. } \\
(2005)\end{array}$ & $\begin{array}{l}\text { Política de gestão de pessoas e imagem corporativa. } \\
\text { Desenvolvimento cultural, tempo livre, hábitos de lazer e esporte. }\end{array}$ \\
\hline $\begin{array}{l}\text { Rodrigues } \\
(2006)\end{array}$ & $\begin{array}{l}\text { Questões políticas, sociais e econômicos, crescimento e segurança profissional no } \\
\text { trabalho. } \\
\text { Satisfação do profissional no trabalho. }\end{array}$ \\
\hline $\begin{array}{l}\text { Alvarez } \\
(2006)\end{array}$ & $\begin{array}{l}\text { Satisfação das necessidades do trabalhador de desenvolver suas atividades na } \\
\text { organização. }\end{array}$ \\
\hline $\begin{array}{l}\text { Diniz de Sá et } \\
\text { al. (2007). }\end{array}$ & $\begin{array}{l}\text { Saúde emocional e clima organizacional. } \\
\text { Aspectos psico-sociais, tecnológicos, físicos ehigiênicos. }\end{array}$ \\
\hline
\end{tabular}

Quadro 1 - Critérios de avaliação de QVT

Fonte: Compilado dos autores: Lacaz (2000); Ayres et al. (2000); Rugiski et al. (2005); Rodrigues (2006); Álvarez (2006); Diniz de Sá et al. (2007).

Verificou-se que um conjunto de fatores pode interferir no desempenho dos funcionários e a conquista da qualidade de vida no trabalho depende de cada pessoa, de sua autoestima e autoimagem, do engajamento profissional e, acima de tudo, de sua postura na transformação da realidade e da consciência de seus direitos e deveres na organização (ALVAREZ, 2006).

Vários autores consideram que a QVT está relacionada ao bem-estar geral dos empregados no desempenho de suas tarefas. Fatores como supervisão, condições de trabalho, salário, benefícios e desafios do cargo afetam a QTV, sendo a natureza do cargo, o fator que envolve mais intimamente o trabalhador. De acordo com Ayres (2000), uma boa vida de trabalho significa um cargo interessante, desafiador e compensador. Ainda, para Handy Diniz de Sá et al. (1978 apud DINIZ DE SÁ, 2007, p. 273) “[...] a QVT influencia ou é influenciada por vários aspectos da vida fora do trabalho, sendo necessária uma análise da vida do trabalhador fora do meio organizacional para que se possa medir a importância e interligação destas duas vidas".

Os estudos são recorrentes em afirmar que para melhorar as condições da qualidade de vida no trabalho deve-se identificar os problemas em cada situação, com a participação efetiva dos sujeitos do processo de trabalho e replanejá-lo, o que envolve sempre um processo de negociação (LAURELL; NORIEGA, 1989, apud LACAZ, 2000). Neste contexto, há diversos modos racionais de fazer o trabalho, não cabendo somente aos gestores esta responsabilidade, mas também aos empregados. Desta maneira, acredita-se acabar com a separação, vinda da administração racional, entre o planejamento e execução de qualquer trabalho. 


\section{PROCEDIMENTOS METODOLÓGICOS}

A presente pesquisa caracteriza-se quanto aos fins como pesquisa exploratório-descritiva. Vergara (2000) define pesquisa exploratória como aquela em que há pouco conhecimento acumulado e sistematizado e tem o objetivo de aprimorar ideias, levantar hipóteses sobre assunto pouco explorado. Como descritiva, para a autora, é a pesquisa que procura obter informações e descrever características de determinada população ou fenômeno.

Classifica-se a abordagem como qualitativa com algum recurso da pesquisa quantitativa, por meio da utilização de estatística simples. A pesquisa qualitativa é definida por Maanem (1979, p. 520) como a que busca "traduzir e expressar o sentido do fenômeno do mundo social e trata-se de reduzir a distância entre indicador e indicado, entre teoria e dados entre contexto e ação".

Foram utilizados alguns requisitos de análise de conteúdo considerada como uma técnica para o tratamento de dados que visa identificar o que está sendo dito a respeito de determinado tema (BARDIN, 1977).

Neste contexto, buscou-se conhecer as inter-relações de sujeitos no seu ambiente natural e estudar um fenômeno em curso como apregoado por Godoy (1995), utilizando-se de multimétodos: análise de documentos; observação dos pesquisadores; e aplicação de questionário semiestruturado. A pesquisa bibliográfica foi realizada tendo como fontes de informação livros, dissertações, teses, artigos em meio eletrônico. Para a pesquisa documental foram utilizados documentos internos fornecidos pela instituição, com intuito de melhor entender o tema Qualidade de Vida no Trabalho.

De acordo com dados institucionais, a população da CEF totaliza 74.638 empregados, sendo que 2.910 trabalham nas Superintendências do Estado de Santa Catarina e 329 especificamente na Superintendência Regional Oeste (SC). A escolha dessa superintendência foi intencional, uma vez que é nessa região, a residência dos pesquisadores, o que facilitou a obtenção dos dados. A superintendência abrange as agências de: Caçador; Campos Novos; Capinzal; Concórdia; Desbravador (em Chapecó); Dionísio Cerqueira; Fraiburgo; Joaçaba; Maravilha; Palmitos; Pinhalzinho; Porto União; São José do Cedro; São Lourenço do Oeste; São Miguel do Oeste; Seara; Videira; Xanxerê; Xaxim; PAB (Posto de Atendimento Bancário) Justiça Federal Chapecó; PAB Justiça Federal Joaçaba; e PAB Uno Chapecó, todas localizadas no Oeste e Extremo Oeste de Santa Catarina. Do total de 329 (100\%) foram devolvidos devidamente preenchidos 180 (54,71\%) questionários.

Como instrumento de coletas de dados utilizou-se questionário semiestruturado, baseado na literatura sobre o assunto, em que constavam itens como: ambiente e condições de trabalho; relacionamento com as chefias e os colegas; crescimento e desenvolvimento profissional e pessoal; carga horária; motivação; e plano de saúde.

A aplicação dos questionários ocorreu nos meses de abril e maio de 2008. Teve início com a solicitação de autorização para realização da pesquisa junto à Superintendência Regional da Caixa. Após a autorização, os questionários foram enviados para os 329 (100\%) empregados, por meio de malote de correspondência interna da empresa.

Para cumprir o objetivo proposto no estudo foram elaborados os quesitos norteadores que estão apresentados a seguir: 


\begin{tabular}{|l|l|}
\hline \multicolumn{1}{|c|}{ Quesitos norteadores } & \multicolumn{1}{c|}{ Características } \\
\hline 1 Dados demográficos dos empregados. & Investigar o perfil dos empregados. \\
\hline 2 Satisfação no trabalho. & $\begin{array}{l}\text { Verificar a satisfação dos empregados quanto as suas } \\
\text { atividades, salário e ambiente de trabalho. }\end{array}$ \\
\hline $\begin{array}{l}\text { 3 Satisfação em relação ao plano de } \\
\text { carreira. }\end{array}$ & $\begin{array}{l}\text { Investigar a percepção e visão com relação ao plano de } \\
\text { carreira na instituição. }\end{array}$ \\
\hline $\begin{array}{l}\text { 4 Qualidade de vida no trabalho. } \\
\text { Relacionamento amistoso. }\end{array}$ & $\begin{array}{l}\text { Identificar o que o empregado entende por qualidade de vida } \\
\text { no trabalho. } \\
\text { Identificar o ambiente preferível dos empregados. }\end{array}$ \\
\hline 5 Saúde pessoal. & $\begin{array}{l}\text { Investigar os entendimentos do trabalhador em relação ao } \\
\text { que está fazendo para ter uma boa saúde. }\end{array}$ \\
\hline Plano de saúde e auxílio alimentação. & $\begin{array}{l}\text { Investigar a satisfação dos trabalhadores sobre o plano de } \\
\text { saúde. } \\
\text { Investigar se o auxílio alimentação é suficiente para supriras } \\
\text { necessidades de uma pessoa. }\end{array}$ \\
\hline $\begin{array}{l}\text { 7 Clima organizacional e plano de } \\
\text { carreira. }\end{array}$ & $\begin{array}{l}\text { Investigar como está o clima organizacional, o plano de } \\
\text { carreira e avaliação profissional na Caixa. }\end{array}$ \\
\hline 8 Questões abertas. & $\begin{array}{l}\text { Como se sente trabalhando na Instituição. } \\
\text { Apresentação de sugestões em relação à QVT. }\end{array}$ \\
\hline
\end{tabular}

Quadro 2 - Quesitos norteadores

Para a tabulação dos dados utilizou-se o software Sphinx Léxica, sendo a análise dos resultados consolidada a partir de quesitos extraídos daliteratura.

\section{A QUALIDADE DE VIDA NO TRABALHO NA PERCEPÇÃO DOS EMPREGADOS DA CEF DO OESTE CATARINENSE}

A Caixa Econômica Federal é uma instituição financeira criada em 1861 sob a forma de empresa pública. Vinculada ao Ministério da Fazenda, a Caixa tem sede e foro na capital da República (Brasília), e atuação em todo o território nacional. Atende clientes bancários e todos os trabalhadores formais do Brasil por meio do Fundo de Garantia do Tempo de Serviço (FGTS), do Programa de Integração Social (PIS), do Seguro-Desemprego, de programas sociais, além de usuários das unidades lotéricas (CEF, [s.d.]).

A forma de ingresso na instituição se dá por meio de concurso público com pontuação mínima estabelecida em edital. Para o ingresso na CEF é exigida a escolaridade de nível médio completo, para exercício do cargo de técnico bancário e escriturário, e graduação para engenheiros e área jurídica.

\section{DADOS DEMOGRÁFICOS DOS EMPREGADOS DA CAIXA}

Na questão de gênero, a pesquisa revelou que 52,22\% dos empregados pesquisados são do sexo masculino e $47,78 \%$ do sexo feminino. As estatísticas nacionais são confirmadas, demonstrando que a população feminina no Brasil é maior que a masculina, mas o gênero feminino apresenta número menor de registro em carteira de trabalho (IBGE, 2008).

Com relação à faixa etária, 7,78\% têm entre 18 e 25 anos; 18,33\% entre 25 e 35 anos; 44,44\% 
entre 36 e 45 anos; 28,33\% entre 45 e 55 anos e apenas 1,11\% têm acima de 56 anos de idade. Observou-se que um percentual menor de empregados possui menos de 25 anos de idade, e um número acentuado de trabalhadores entre 36 e 45 anos de idade. Isto sugere que houve um período em que a Caixa não contratou novos empregados e que, nas contratações posteriores, muitos jovens ingressaram.

No aspecto escolaridade, 8,89\% têm ensino médio; $11,11 \%$ estão cursando o ensino superior; 48,89\% possuem curso superior completo e 31,11\% têm pós-graduação somente em nível de especialização. Há diferenças em percentuais, referente ao nível de escolaridade, para cada gênero, sendo que $51,85 \%$ do sexo masculino possuem maior escolaridade que os pesquisados do sexo feminino, que é de $48,15 \%$.

Em relação à renda individual de cada empregado, destaca-se que os melhores rendimentos estão concentrados com os empregados do sexo masculino em todas as faixas salariais.

Os rendimentos recebidos pela categoria dos bancários são superiores a da média da população brasileira, que possui rendimentos médios de $\mathrm{R} \$ 785,80$ mensais para os homens e de $\mathrm{R} \$ 547,00$ mensais para as mulheres, totalizando uma média geral de rendimentos, nos mais diversos setores de trabalho, de $\mathrm{R} \$ 692,10$ mensais por trabalhador (IBGE, 2008).

Conforme dados obtidos na pesquisa, constatou-se que os homens têm rendimentos superiores aos das mulheres, ou seja, os cargos ou funções mais bem remuneradas são exercidos por trabalhadores do sexo masculino.

Com relação ao tempo de trabalho na instituição, 25,56\% trabalham a menos de 5 anos; e 12,22\% entre 6 e 10 anos. No período entre 11 e 15 anos de prestação de serviços não houve nenhuma resposta. Já 44,44\% dos empregados trabalham entre 16 e 20 anos na instituição; 5,56\% entre 21 e 25 anos; e 12,78\% dos respondentes estão na Caixa a mais de 25 anos. Contudo, evidenciou-se que, em alguns períodos, houve pouca ou nenhuma contratação.

No item sobre cargos/funções exercidos pelos empregados, 28,33\% são técnicos bancários, $16,11 \%$ atendem o setor de caixa; 7,78\% são assistentes administrativos, 3,89\% exercem a função de tesoureiro, 20,00\% são gerentes de segmento, 4,44\% gerentes gerais e 19,44\% dos respondentes exercem outras funções existentes na instituição e que não foram mencionadas pelos entrevistados.

Com relação aos cargos de técnico bancário, Caixa-PV e assistente administrativo, estes são exercidos, em sua maioria, pelo gênero feminino. Ao passo que as funções de tesoureiro, gerente de segmento e gerente geral são exercidas em percentual maior por homens. Analisado o período de trabalho diário dos empregados, 58,89\% trabalha 6 horas por dia, sem contar horas-extras, ou seja, tem contrato com a Caixa de 30 horas semanais e, 41,11\% dos respondentes trabalham 8 horas diárias, tendo contrato de 40 horas semanais. Observou-se, pelas anotações nos questionários, que as horas-extras são realizadas com frequência.

\section{A SATISFAÇÃO NO TRABALHO}

A compensação dos trabalhadores de uma empresa quanto à remuneração, ambiente de trabalho, acúmulo e sobrecarga de trabalho, poderá pesar na decisão de permanecer ou não nela. Com referência a satisfação em trabalhar na CEF, 90,00\% dos respondentes estão satisfeitos; 8,33\% não estão satisfeitos e 1,67\% não responderam. Entende-se que, apesar de 
haver, em alguns aspectos e particularidades nas quais a satisfação dos respondentes está em percentuais menores, no geral, os pesquisados aprovam as políticas de QVT dainstituição.

A percepção quanto aos aspectos remuneração, 40,00\% consideram o salário que recebem como bom e condizente com o cargo/função que exercem. Para 45,00\%, a remuneração está regular; outros $2,78 \%$ responderam que a remuneração está muito boa, enquanto que para 11,11\% o salário está ruim e 1,11\% não responderam.

Os pesquisados apresentaram argumentos mostrando que, à medida que o empregado recebe salários maiores, há também maiores responsabilidades tais como: maior carga horária; aumento de trabalho; e mais compromissos. Neste sentido, uma questão buscava saber se o acúmulo de trabalho causa estresse e afeta as atividades/particulares. Sobre este questionamento, $71,67 \%$ evidenciaram sentirem-se afetados pelo estresse e $67,78 \%$ evidenciaram que a sobrecarga de trabalho afeta sim, as suas atividades particulares.

Um aspecto externo que pode influenciar na satisfação do empregado é o ambiente de trabalho (layout). Sobre este aspecto, buscou-se saber dos pesquisados como está o ambiente de trabalho, 3,89\% respondeu que está ótimo; 13,89\% muito bom; 48,33\% sinalizaram que está bom. Para 28,89\% o layout está regular e para 5,00\% está ruim. Com relação à questão sobre qual mudança que deveria ser feita no layout das agências foram apresentaram as seguintes sugestões: adequação das mesas e cadeiras para uma melhor postura ergonômica; mesas maiores para apoio de material necessário no atendimento ao cliente durante o expediente; maior espaço nos guichês dos caixas; e melhorias nos sistemas de climatização das agências.

\section{SATISFAÇÃo EM RELAÇÃo AO PLANO DE CARREIRA NA INSTITUIÇÃo}

A satisfação e permanência dos trabalhadores em uma empresa também estão relacionadas com o plano de carreira. Buscou-se saber, como os empregados da Caixa percebem o plano de carreira e se pretendem seguir na instituição ou buscar outras condições de trabalho, tais como: planos de saúde; auxílio alimentação; e outros benefícios em outras empresas.

A satisfação e permanência dos trabalhadores na empresa têm relação com o plano de carreira. Conforme dados da pesquisa, 86,69\% sinalizaram que pretendem permanecer trabalhando na CEF. Um paradoxo em relação ao percentual de permanência e avaliação do plano de carreira, pois para 44,44\%, o plano de carreira é bom; 33,33\% avaliam como regular, para outros $8,89 \%$ o plano de carreira é muito bom e, para 1,11\% o plano de carreira é ótimo; $12,22 \%$ avaliaram o plano de carreira como ruim.

Os dados mostraram ainda que, 86,67\% dos pesquisados não pretendem sair da instituição para trabalhar em outra empresa ou órgão público, o que confirma a pretensão em seguir carreira na instituição. Contudo, em outro questionamento, 41,46\% dos respondentes declararam que, se outra empresa oferecer melhor proposta de cargos e salários, plano de carreira, entre outros benefícios, sairiam da CEF, enquanto 42,78\% responderam que talvez aceitassem uma proposta externa.

\section{QUALIDADE DE VIDA NO TRABALHO}

Neste quesito foram elencadas questões para saber dos empregados o que é qualidade de vida no trabalho em seu entendimento, no qual os pesquisados puderam assinalar três dimensões, das quais acreditam serem as mais condizentes, de acordo com a sua visão, com o conceito de 
QVT.

Esta questão buscou saber o que é qualidade de vida no trabalho e os dados revelaram que $74,44 \%$ afirmaram que é necessária a satisfação e realização pessoal; 58,33\% declararam que é adequada e satisfatória a recompensa salarial, já 42,22\% observou que é necessário o crescimento e segurança profissional. Para outros 40,00\% é necessário ter segurança e saúde no trabalho, 23,33\% sinalizaram que, para ter qualidade de vida no trabalho é preciso ter respeito aos direitos do trabalhador. Destaca-se que a percepção dos empregados da Caixa condiz com as dimensões encontradas, a partir do estudo da literatura daárea.

Na percepção dos empregados quanto às dimensões da qualidade de vida no trabalho que a Caixa mais oferece aos seus trabalhadores, 58,33\% observaram que são as necessidades básicas satisfeitas, tais como: fisiológicas, de segurança, sociais e de autoestima; 50,00\% evidenciaram que, o que a instituição mais oferece é oportunidade de contínuo crescimento e segurança profissional; para $48,89 \%$ é a integração e o relacionamento amistoso no ambiente de trabalho. Ainda, para 79,44\%, o clima é amistoso e há bom relacionamento entre os colegas e visualiza-se o empenho de todos para atingir as metas da instituição.

\section{SAÚDE PESSOAL}

A prática de atividades físicas é um fator importante para o bom desempenho do trabalho e, principalmente, para a saúde das pessoas. Há uma preocupação cada vez maior, por parte dos responsáveis pelas empresas, em cuidar da saúde de seus trabalhadores. Neste quesito, foi constatado que 84,44\% não fazem ginástica laboral na instituição; 15,00\% responderam que fazem atividades físicas por conta própria. Partindo do entendimento e prerrogativa da boa saúde para o trabalho, um dos respondentes escreveu que: "faço ginástica laboral por conta própria, por que sei dos benefícios que me traz e tenho orientação do meu personal training, da academia onde pratico atividades físicas regularmente".

Dos pesquisados que praticam ginástica laboral, 68,75\%, fazem ginástica laboral duas vezes por semana, ou seja, apenas $8,89 \%$ do total dos respondentes praticam ginástica laboral duas vezes por semana. Apenas 0,56\% dos respondentes afirmaram que fazem exercício físico todos os dias. Percebeu-se que os pesquisados visualizam os benéficos da ginástica laboral para a saúde, pois 93,89\% dos trabalhadores acreditam que a prática de ginástica laboral pode diminuir os efeitos de problemas localizados como: Distúrbios Ósteomusculares Relacionados ao Trabalho (DORT) e Lesões por Esforços Repetitivos (LER). Verificou-se que a maioria dos trabalhadores que não faz ginástica laboral apresenta problemas relativos ao horário diferenciado. Em resumo, verificou-se que um percentual significativo dos empregados pesquisados pratica algum tipo de atividade física fora dotrabalho.

Os pesquisados acreditam ainda que a prática de atividades físicas melhora o desempenho pessoal e profissional, sendo que, dos pesquisados 98,33\% declararam que a prática de atividade física melhora a disposição para o trabalho e diminui os problemas de saúde. Um dos respondentes evidenciou o seguinte: "Observo que desde que comecei a praticar atividades físicas, minha disposição para o trabalho melhorou, o estresse e meus problemas de saúde diminuíram e tenho mais disposição para com minha família". Também para ele, a iniciativa da prática de atividades físicas é pessoal na maioria dos casos, sendo que, para $61,11 \%$ dos pesquisados, a instituição não incentiva seus empregados a fazerem atividades físicas. 


\section{BENEFÍCIOS: PLANO DE SAÚDE E AUXÍLIO ALIMENTAÇÃO}

Nesta dimensão, são apresentados os dados da avaliação, por parte dos empregados, em relação ao plano de saúde e auxílio-alimentação, em que $52,22 \%$ avaliaram o plano de saúde como bom; $47,78 \%$ citaram que não é bom, outros $64,44 \%$ sinalizaram que o plano de saúde não atende às suas necessidades, pela falta de profissionais da área da saúde credenciados ao plano da instituição, principalmente nas cidades do interior, sendo necessário deslocarem-se a centros maiores para consultas e tratamento quando necessário.

Com relação ao plano de alimentação, 71,11\% citaram que o valor recebido mensalmente é suficiente para a alimentação saudável de uma pessoa.

\section{CLIMA ORGANIZACIONAL E PLANO DE CARREIRA NA CAIXA}

O bom clima organizacional entre os trabalhadores e a empresa, é importante para o adequado desempenho e desenvolvimento da organização. Neste quesito, foram elencadas questões acerca do tema para o entendimento de como os empregados se sentem por trabalhar na Caixa.

Buscou-se saber dos pesquisados qual a pretensão em seguir o plano de carreira na empresa, se a Caixa apoia a continuidade dos estudos dos empregados e, quanto à avaliação de desempenho. Nas falas apresentadas verificaram-se os seguintes sentimentos pelo fato de trabalhar na Caixa: segurança; satisfação; realização profissional e pessoal; bem-estar; valorização e conforto por fazer parte desta empresa, que possui e confere ao empregado, segundo os respondentes, certo status no seu círculo social. Também sinalizaram sobre outras situações, conforme se transcreve: "Tenho orgulho de trabalhar na empresa, pois gosto do que faço, porém, pesa muito a questão salário, por isso penso em mudar de emprego".

Outro entrevistado relacionou sua satisfação às próprias funções da instituição: "Sinto orgulho de trabalhar em uma empresa que ajuda no desenvolvimento do Brasil, seja no campo habitacional, fundos e programas sociais ou no repasse de recursos da união".

Ainda, outro respondente observou a melhoria de trabalho ao apontar que "Pode não ser a melhor empresa de se trabalhar, mas sei que a Caixa está melhorando a cada dia, e gosto do serviço que faço e do atendimento a pessoas".

Também se verificou na fala, satisfação com a instituição e características de ser uma empresa pública ao declarar que: "Sinto-me uma pessoa de sorte, não é melhor que outra profissão, porém, acho que a empresa pública promove muito mais o reconhecimento coletivo do que $o$ individual".

Alguns dos trabalhadores ainda acrescentaram que os empregados devem estar atentos ao seu bem-estar na organização, na seguinte fala: "A minha opinião é de que, a partir do momento em que não nos sentimos bem na empresa que trabalhamos, devemos procurar alternativa. Até o momento estou me sentindo bem".

Também dentre as questões elencadas apareceu a imagem da instituição, ao colocarem que:

Para mim o trabalho é bom, dá segurança. É um lugar onde podemos escolher o período de férias. Temos um nome (CAIXA) que nos dá segurança. 
Sinto-me uma pessoa realizada, muito feliz e com uma carreira brilhante pela frente e, que tudo vai depender de meu interesse e desempenho.

Outros ainda sentem-se bem por trabalhar em uma empresa pública de grande porte, apesar dos problemas existentes. "Fazer parte de uma grande empresa é bom, pois, oferece condições de crescimento profissional, apesar de apresentar alguns problemas".

Em alguns setores, o contato com as pessoas é avaliado como positivo e importante, como relatam os respondentes:

Independente do setor no qual se trabalha na Caixa tem-se algum contato com clientes.

Sinto-me bem por trabalhar em um setor de grande fluxo de pessoas, posso muitas vezes, atuar como agente de conscientização e transformação social. 0 que é gratificante.

Por outro lado, parte dos respondentes evidenciou estar descontente por ter pouca oportunidade de desenvolvimento de suas habilidades profissionais e humanas. Acreditam que além do salário, também o reconhecimento profissional deveria ser maior. Desta forma, verificou-se a seguinte fala: "Sinto um desânimo por ter tanto trabalho, ganhar pouco, ter de aguentar todos os dias problemas de sistema e não ver perspectivas de crescimento a curto prazo".

Com o advento da globalização e inovação de tecnologias, customizando e sistematizando os sistemas de trabalho, cada vez mais as empresas tem buscado agilidade nos processos e atendimento ao cliente. Porém, conforme relatos de respondentes, os problemas com os sistemas eletrônicos utilizados pela Caixa são muito frequentes, na visão dos respondentes, e dois relataram que:

Frequentemente, para atender um cliente, demoro o tempo de atender três ou quatro pessoas, por que o sistema está lento ou até mesmo não funciona, tendo que por vezes trabalhar com o sistema em off.

Estou muito estressado, pois, a sobrecarga de trabalho me faz pensar em mudar de emprego assim que tiver uma oportunidade.

A inadequação das tecnologias pode impactar a percepção de bem-estar no trabalho e gerar tensão entre os empregados.

No tocante a formação e desenvolvimento promovidos pela Caixa, quando questionados sobre os cursos da Universidade Caixa, $89,44 \%$ dos pesquisados declararam que os cursos ajudam a melhorar o desenvolvimento profissional no trabalho; $10,44 \%$ assinalaram que estes cursos não acrescentam nada ao desenvolvimento profissional e pessoal; e 0,56\% não responderam esta questão.

Com relação à avaliação de desempenho, do ponto de vista dos respondentes, a questão foi avaliada do seguinte modo: $0,56 \%$ apontam que os procedimentos de avaliação de desempenho está ótimo; 8,89\% declararam que está muito bom; para 46,67\%, a forma de avaliação está boa; já 33,33\% declararam que está regular; 8,89\% destacaram que o sistema de avaliação está ruim; e 0,56\% não responderam esta questão. Para mais de 50,00\% dos pesquisados, os procedimentos de avaliação de desempenho, de forma geral, está adequado, porém, houve alguns comentários sugerindo avaliações e treinamentos mais freqüentes, 
relacionados aos produtos e serviços e quando dos novos lançamentos ou mudanças na operacionalização destes.

Sobre a avaliação de desempenho, os respondentes elencaram itens relativos à ascensão de cargos e qualidade do atendimento ao cliente como se transcreve a seguir:

\footnotetext{
Sinto-me frustrado, pois, a ascensão de cargos muitas vezes não depende da capacidade, desempenho e vontade do empregado e, sim, dos avaliadores que escolhem por afinidade.

As avaliações deveriam ser mais frequentes, observando a qualidade do atendimento ao cliente, pois, assim o empregado irá se esforçar mais em atender bem.

Deveríamos ter mais treinamento relacionado ao produto quando do lançamento destes, para que pudéssemos dar melhores esclarecimentos ao cliente na hora da venda.
}

O próximo assunto apresentado foi a comunicação interna nas empresas que é de fundamental importância para o bom andamento e fluxo de informações, agilidade nos processos de produtividade e envolvem as mais diversas operações a serem realizadas.

Ao questionar os pesquisados para saber como percebem o sistema de comunicação e informações internas da Caixa, 4,44\% dos respondentes declarou que está ótimo; 16,11\% afirmaram que está muito bom; para 58,89\% a comunicação está boa; já para 17,78\% o sistema de comunicação e informações da caixa está regular; e 2,78\% declararam que está ruim. Alguns pesquisados sinalizaram que há muita informação repetida, e outro apresenta uma fala sobre o procedimento que avalia as informações de e-mail conforme se transcreve:

Há muita informação repetida no e-mail, o que pode impedir o recebimento de outras informações importantes.

A caixa de mensagens da agência é administrada por uma pessoa que filtra e repassa a pessoa a que corresponde à informação, facilitando o trabalho de todos.

As observações foram as mais diversas, desde que há poucos empregados para o volume de trabalho, necessitando mais contratações, até observações relacionadas ao plano de carreira e salários. Um dos respondentes declarou: "Há poucos empregados para tanto trabalho, é impossível atender bem quando é necessário apurar demais no atendimento".

Já outro observou: “Às vezes sinto-me desconfortável por ver que pessoas ficam esperando muito tempo para serem atendidas, sendo que também eu não gosto de ficar esperando muito para ser atendida".

Outro ainda destacou: "Gostaria que o plano de cargos e salários fosse melhor, que tivesse melhor avaliação, todo ano é uma briga para conseguir uma negociação”.

As respostas apontam para a satisfação dos empregados com seu trabalho na Caixa, contudo, demonstram que há pontos que precisam ser observados para produzir melhorias contínuas na direção da QVT nesta organização.

\section{CONSIDERAÇÕES FINAIS}

0 presente estudo teve seus objetivos atendidos em sua totalidade. Observa-se que, com o aumento da competição entre as instituições bancárias, estas têm buscado diversificar e ampliar suas atividades, fator que gera novos desafios aos trabalhadores e produz impactos 
sobre sua QVT. Este estudo contemplou aspectos específicos da Caixa Econômica Federal, na Superintendência do Oeste de Santa Catarina e apresentou diferentes percepções e níveis de satisfação entre os empregados desta região.

Dentre os pontos que mais geram satisfação dos empregados da Caixa, está a estabilidade e a confiança na instituição. Os entrevistados $(86,69 \%)$ pretendem permanecer na organização e entendem que a Caixa contribui para atender às necessidades básicas dos empregados, tais como: fisiológicas, de segurança, sociais e de autoestima. Contudo, um grupo expressivo de trabalhadores declarou ser fortemente afetado pelo estresse do trabalho $(71,67 \%)$ e estar com grande sobrecarga de trabalho que afeta as suas atividades particulares $(67,78 \%)$.

Já as principais oportunidades de melhoria que os empregados percebem são: promoção de treinamentos nos lançamentos de produtos; reformulação geral dos sistemas e aplicativos; e, em relação ao plano de saúde, a caixa deveria fazer convênio com outra instituição que presta este tipo de atendimento no Estado; melhoria nos planos de saúde com aumento de credenciados; a Caixa deveria valorizar mais os investimentos feitos em educação como forma de iniciativas de cada empregado; existe o incentivo para os estudos, mas a sobrecarga de trabalho e a deficiência dos sistemas desanimam o empregado na hora de fazer os cursos; melhorar o plano de cargos e salários; necessidade de contratação de mais empregados e disponibilizar aos funcionários tempo para realizar os cursos da Universidade Caixa no ambiente interno.

Como reflexão final, sinaliza-se os muitos desafios que se apresentam para a gestão de pessoas, entre estes, descobrir como seria possível compatibilizar eficiência administrativa e qualidade de vida para o trabalhador, além de conciliar os interesses individuais com critérios de sustentabilidade para todo o conjunto social, foco último da atuação da Caixa.

O presente trabalho restringiu-se à Superintendência Regional do Oeste de Santa Catarina e pelo fato de a instituição atuar no país inteiro, recomenda-se o desenvolvimento de pesquisas sobre QVT na visão de empregados de outras superintendências da CEF.

\section{REFERÊNCIAS}

ALVAREZ, N. R. Qualidade de vida no trabalho: Estudo de Caso em uma Prefeitura de médio porte. 2006. Disponível em:

<http://publica.fesppr.br/index.php/rnti/article/viewArticle/v1n2ART7>. Acesso em: 06 set. 2011.

AYRES, K. V. SILVA, I. P. SOUTO-MAIOR, R. C. Stress e Qualidade de Vida no Trabalho: a percepção de profissionais do setor de hotelaria. [2000]. Disponível em: <http://www.biblioteca.sebrae.com.br/bds/BDS.nsf/100F0E78C3AE8EA803256FCB005FBC 4D/\$File/NT000A5432.pdf >. Acesso em: 06 abr. 2011.

BARDIN, l. Análise do conteúdo. São Paulo: Edições 70,1977.

CAIXA ECONOMICA FEDERAL (CEF). A Caixa: o banco que acredita nas pessoas. [s.d]. Disponível em: <http://www.caixa.gov.br/acaixa/index.asp>. Acesso em: 20 set. 2011.

DINIZ de SÁ, M. A. D.; HONÓRIO, J. B.; OLIVEIRA, R. C. R.; VIANA, K. M. P. Qualidade de Vida no Trabalho Docente: uma questão de prazer. 2007. Disponível em: <http://www.anpad.org.br/evento.php?acao=trabalho\&cod edicao subsecao=280\&cod even to edicao $=33 \&$ cod edicao trabalho=7 591>. Acesso em: 06 set. 2011. 
FERREIRA, M. C.; ALVES, L. TOSTES, N.. Gestão de Qualidade de Vida no Trabalho (QVT) no serviço público federal: o descompasso entre problemas e práticas gerenciais. Psic.: Teor. $e$ Pesq. [online]. 2009, v. 25, n.3, p. 319-327. Disponível em: <http://www.scielo.br/scielo.php?script=sci arttext\&pid=S01027722009000300005\&lng=pt\&nrm=iso >. Acesso em: 12 set. 2011.

GODOY, A. S. Introdução à pesquisa qualitativa e suas possibilidades. Revista de Administração de Empresas, São Paulo, v. 35, n.2, p.57-63, mar./abr. 1995.

INSTITUTO BRASILEIRAO DE GEOGRAFIA E ESTATÍSTICA (IBGE) Disponível em: <http://www.ibge.gov.br>. Acesso em: 18 set. 2011.

LACAZ, F. A. C. Qualidade de vida no trabalho e saúde/doença. 2000. Disponível em: $<$ http://redalyc.uaemex.mx/pdf/630/63050113.pdf>. Acesso em: 06 out. 2011, p.151-161

LEITE, J. V.; FERREIRA, M. C.; MENDES, A. M.. Mudando a gestão da qualidade de vida no trabalho. Rev. Psicol., Organ. Trab. [online]. 2009, v.l.9, n.2, p. 109-123. Disponível em: $<$ http://pepsic.bvsalud.org/scielo.php?pid=S1984$66572009000200010 \&$ script $=$ sci arttext. $>$.

Acesso em: 20 set. 2011.

LIMONGI-FRANÇA, A. C. Qualidade de Vida no Trabalho (QVT): Conceitos e praticas nas empresas da sociedade pós-industrial. 2. ed. São Paulo : Atlas, 2007.

MAANEM, J. V. Reclaiming Qualitative Methods for Organizational Research: A Preface. Administrative Science Quartely, v. 24 n. 4 December 1979. p. 520, 526.

RUGISKI. M.; PILATTI. L. A.; KOVALESKI. J. L. Qualidade De Vida no Trabalho: um olhar sobre o tempo livre dos trabalhadores de uma indústria metalúrgica. 2005. Disponível em: <http://www.ergonomia.ufpr.br/PB\%20qv\%20tempo\%20livre.pdf > . Acesso em: 06 abr. 2011.

RODRIGUES, M. V. C. Qualidade de vida no trabalho: Evolução e Análise no nível gerencial. Rio de Janeiro: Vozes, 2006.

SíCOLI, C. R. Qualidade de vida e fontes de pressão no trabalho do consultor organizacional em Belo Horizonte. 2003. Dissertação (Mestrado em Administração). Belo Horizonte: UFMG, 2003.

VERGARA, S. C. Projetos e relatórios de pesquisa em administração. 3. ed. São Paulo: Atlas, 2000. 